\title{
Editorial
}

\section{Breves reflexões acerca do uso da História e sobre o historiador da Antiguidade no contexto atual de pandemia}

\author{
Brief reflections on the use of history and the historian of antiquity in the \\ current context of the pandemic.
}

\section{Felipe Nascimento de Araujo ${ }^{1}$}

1 Doutorando do Programa de Pós-Graduação em História da Universidade do Estado do Rio de Janeiro (PPGH/UERJ). Pesquisador integrante do Núcleo de Estudos da Antiguidade (NEA/UERJ) e professor do Curso de Especialização em História Antiga e Medieval da UERJ (CEHAM/UERJ). Bolsista da Coordenação de Aperfeiçoamento de Pessoal de Nível Superior (CAPES) de doutorado. Editor da Revista NEARCO. Email: felipefmna@gmail.com.

A História enquanto campo de conhecimento, mesmo antes de ser sistematizada como disciplina acadêmica no século XIX, frequentemente tem sido evocada e repensada nas sociedades humanas em épocas de grave crise, conflitos, rupturas e questionamentos acerca do próprio papel do homem ao longo dos séculos. Tal colocação se relaciona com a noção "pedagógica" da História enquanto uma "Mestra da Vida", Historia Magistra Vitae citada por Cícero no século I a.C., concebida como um campo que compreende "múltiplas experiências alheias, das quais nos apropriamos com um objetivo pedagógico; ou, nas palavras dos antigos, a história (que) deixa-nos livres para repetir sucessos do passado" no lugar de incorrer com os erros no tempo presente (KOSELLECK, 2006, p. 42). Conforme Reinhart Koselleck, ao longo de centenas de anos a história teria servido como uma "escola" que possuiria um caráter instrutivo prático presente na literatura histórica e política até a Era Moderna, onde muitos negócios jurídicos eram baseados em deduções históricas que eram utilizadas por governantes ${ }^{1}$ como modelos ideais de administração e conduta.

\footnotetext{
${ }^{1}$ Um exemplo seria o relato de Frederico o Grande em suas memórias [Denkwürdigkeiten] que afirma repetidas vezes que a "história é a escola dos governantes, desde Tucídides até Commynes, Cardeal Retz
} 
NEARCD: Revista Eletrônica de Antiguidade 2020, Volume XII, Número I - ISSN 1982-8713

Núcleo de Estudas da Antiguidade -NEA

Universidade do Estada do Rio de Janeiro

ISSN 1982-8713

Esta concepção da História se relaciona com uma noção pragmática de sua utilização, na qual esta deve servir a finalidades específicas que atendam às demandas de uma determinada sociedade. Deve-se destacar que o próprio Koselleck cita um ceticismo básico acerca de tal noção, expondo que a História não se resume a uma dimensão pedagógica, do "aprender alguma lição", pois esta enquanto Geschichte ${ }^{2}$ basta por si mesma, possuindo uma qualidade temporal própria onde "diferentes tempos e períodos de experiência, passíveis de alternância, tomaram o lugar outrora reservado ao passado entendido como exemplo". Perspectiva esta que se coaduna com a colocação de Paul Veyne (1998, p. 59) que define que "o conhecimento histórico tem a sua finalidade nele mesmo" e não por algum tipo de relação de valores pautados em um pragmatismo ou a uma utilidade imperiosa. ${ }^{3}$ Neste caso, a curiosidade do historiador e a seleção de suas temáticas pode ocorrer, segundo Veyne, por conta de uma intenção que pode ser partidária ou não, mas que no final das contas busca em alcançar uma verdade sobre o passado. ${ }^{4}$ Além disso, devemos apontar igualmente que o uso da Historia Magistra Vitae como uma forma de "ensinar lições para que não se

ou Colbert. Ele acredita ter aproximado sua capacidade combinatória graças à continua comparação entre casos anteriores" (KOSELLECK, 2006, p. 46) utilizando a história como um meio, um manual, para orientar suas ações políticas.

${ }^{2}$ A concepção da História enquanto "história em si" (die Geschichte selbst) cunhada por Koselleck referese a uma noção que é oposta à velha história [Historie], pois organizou de maneira nova a relação entre passado e futuro. Neste contexto, o conceito de História de Koselleck abre um novo espaço de experiência a partir de uma qualidade temporal própria (KOSELLECK, 2006, p. 47).

${ }^{3}$ Neste caso, Paul Veyne (1992, p. 59) afirma que o interesse em uma obra história não é produzida somente pelos valores que uma temática possui, mas sim pela simples existência dela. Um exemplo seria a História da Guerra do Peloponeso de Tucídides, no qual Veyne coloca "que razão teríamos para nos interessar pela Guerra do Peloponeso, se não fosse Tucídides estar presente para provocar esse interesse? A influência dessa guerra nos destinos do mundo foi, praticamente, nula, enquanto as guerras entre os estados helenísticos, conhecidas na França apenas por cinco ou seis especialistas tiveram um papel decisivo no destino da civilização na Ásia" e em toda cultura ocidental. Ainda que seja discutível a posição do autor acerca da importância de Tucídides na contemporaneidade, é importante notarmos como esta noção oposta à Historia Magistra Vitae deve ser considerada nos debates atuais sobre o uso da História.

${ }^{4}$ Desse modo, é preciso salientar impreterivelmente que o profuso debate acerca dos usos da História seja por uma via pragmática ou uma via situada em sua própria epistemologia se desenvolveu especialmente ao longo do século XX, estando longe de um esgotamento e sendo demasiado longo para ser citado de modo satisfatório neste Editorial. 
NEARCD: Revista Eletrônica de Antiguidade 2020, Volume XII, Número I - ISSN 19882-8713

Núcleo de Estudas da Antiguidade -NEA

Universidade do Estada do Rio de Janeiro

ISSN 1982-8713

repita os erros do passado" pode esbarrar em possíveis problemas teóricos ou metodológicos na pesquisa histórica, pois cada época possui sua historicidade e especificidades que são aplicáveis somente ao seu contexto histórico, ou seja, encarar que eventos ("erros" ou "acertos") passados possam se repetir de modo sincrônico em nosso tempo presente seria uma desconsideração das particularidades de cada período histórico, o que pode acarretar em um anacronismo na visão do historiador.

No entanto, mesmo considerando esta dimensão de que o conhecimento histórico basta por si mesmo, é inegável que o contexto histórico no qual estamos inseridos nos fornece uma série de questionamentos e, de certo modo, orientações em nossos estudos, análises e de seleções de temas e/ou documentos. Dito isso, os cenários atuais referentes à pandemia do novo Corona Vírus (Covid-19), assim como suas implicações dentro do contexto político, social e econômico de todos os países do planeta, certamente acarretarão em uma série de reflexões a serem feitos não somente por outras áreas da comunidade acadêmica (especialmente as biomédicas, obviamente), mas também pelos historiadores. A grande profusão de artigos e trabalhos publicados na categoria de preprints ${ }^{5}$ de diversas áreas neste primeiro semestre de 2020 demonstra claramente como as demandas do tempo presente podem influenciar decisivamente na produção intelectual da ciência, considerando que a demanda se concentra principalmente na área médica devido à necessidade imediata de se descobrir uma cura. O fato desta crise sanitária não ter possuído precedentes dentro do mundo globalizado pós-década de 70 aponta para a existência de uma urgência geral e de uma série de inquietações decorrentes não somente da questão pandêmica e das pesquisas

\footnotetext{
${ }^{5} \mathrm{O}$ preprint seria "uma versão de um manuscrito antes da avaliação por pares, os quais certificam ou não sua publicação formal em um periódico. O preprint é depositado pelo autor correspondente em um servidor de preprints, geralmente temático, seguindo procedimentos públicos. A versão preprint pode ser um avanço ou uma versão incompleta, porém o mais comum é uma versão final". Os preprints têm sido fundamentais nas áreas das ciências biomédicas no contexto atual de pandemia nas pesquisas que têm buscado uma cura ou vacina. Para maiores informações sobre os preprints consultar: https://blog.scielo.org/blog/2016/11/22/o-que-e-este-tema-dos-preprints/\#.X02nvO-SnlU. Acessado em 12 de julho de 2020.
} 
sobre uma possível vacina, mas igualmente das políticas de isolamento social estão sendo implementadas ao redor de todo o mundo (em maior ou menor grau, deve-se destacar). Outros aspectos particulares a serem citados são: a instauração maciça do home-office como forma de trabalho, a adoção do ensino remoto em diversas Universidades brasileiras, e a necessidade de se adequar a realização de muitas pesquisas e trabalhos acadêmicos dentro do ambiente virtual, no qual a internet possui papel preponderante e indispensável.

Sendo assim, torna-se necessário trazer certas questões: como as abordagens dentro do campo História Antiga se situam dentro de tal cenário atípico e inédito em nosso "recente" século XXI? Quais são os desafios do historiador da Antiguidade frente às demandas das sociedades e nações? Como o estudo da Antiguidade se articula dentro dos saberes acadêmicos? A Antiguidade pode oferecer algum tipo de "lição" dentro de uma perspectiva Historia Magistra Vitae? Precisamos sublinhar que tais questionamentos não estão sendo levantados com objetivo de serem efetivamente esgotados ou respondidos neste pequeno editorial, mas sim como uma tentativa de promover reflexões acerca de como nós, historiadores da Antiguidade, nos inserimos dentro deste contexto de pandemia mundial e crescente expansão das atividades remotas não-presenciais. Alguns exemplos que ilustram as nossas mudanças do cotidiano são: aulas em EAD (Educação a Distância); Seminários e Congressos realizados de forma exclusivamente online; o incentivo de divulgação de materiais e acervos online por instituições como Universidades e Museus de todo o mundo; cursos de extensão sendo ministrados via plataformas populares como o Youtube; entre outras atividades.

Certamente pode-se sublinhar que, apesar dos pesares envolvendo as adaptações das sociedades à pandemia (especialmente 0 isolamento e suspensão das atividades não-presenciais), a expansão de atividades remotas utilizando a internet como meio de integração nos oferece novas possibilidades não somente de Ensino, Pesquisa e Extensão, mas igualmente expandem nossas possibilidades metodológicas e do acesso a documentos. Um exemplo seria o possível aumento da disponibilização dos 
NEARCD: Revista Eletrônica de Antiguidade 2020, Volume XII, Número I - ISSN 1982-8713

Núcleo de Estudas da Antiguidade -NEA

Universidade do Estada do Rio de Janeiro

ISSN 1982-8713

acervos online dos museus, algo já extensamente realizado antes da pandemia do Covid19 por museus notáveis como o British Museum, Museu do Louvre e Metropolitan Museum of Art de Nova lorque; nos quais objetos arqueológicos são imprescindíveis para o desenvolvimento de pesquisas em História Antiga que analisam a cultura material. Além disso, é interessante observar como a alta profusão de palestras e seminários a distância potencializam as oportunidades de participação em eventos internacionais e regionais, bem como proporcionam a reflexão sobre novas formas de integração da ciência aberta utilizando a internet. Pierre Lévy provavelmente não imaginou estes avanços tecnológicas atuais ao escrever em 1993 (nos primórdios da internet) sobre as possibilidades da informática na educação e pesquisa, no qual curiosamente cita como exemplo uma aula universitária informatizada com a temática de Cícero e Roma (LÉVY, 1993, p. 31-32).

Desse modo, apresentamos com certa esperança e otimismo esta edição da NEARCO - Revista Eletrônica de Antiguidade em 2020 com artigos de temática livre, sendo um número total de 10 (dez). Mesmo com todas as vicissitudes, peculiaridades e problemas de nossa atualidade marcada pela pandemia, a intensificação do uso da internet e das atividades remotas pode oferecer novas potencialidades e possibilidades metodológicas de pesquisas em Antiguidade, principalmente as realizadas em nosso contexto geográfico da América Latina, situada a quilômetros dos territórios europeus, africanos e asiáticos (cenário da maior parte das temáticas de História Antiga). Além disso, destacamos também a possibilidade de pensarmos temáticas distintas com um olhar diferenciado, como por exemplo as (prováveis) vindouras novas análises sobre a peste na Atenas Clássica ${ }^{6}$ vistas a partir do nosso olhar proveniente de nosso próprio contexto pandêmico, facilitando a aplicação de olhares alternativos ao historiador. Em

\footnotetext{
6 Segundo Victor Ehrenberg, a peste em Atenas teria iniciado seu outbreak ("surto" em tradução aproximada) em aproximadamente 430 a.C. avançando progressivamente do porto do Pireu ao longo de toda a pólis. Milhares de pessoas pereceram à doença, tendo Péricles falecido desta e Tucídides pego também, mas sobrevivido. Ainda que haja uma descrição precisa dos sintomas da doença por Tucídides (Thuc. livro 2 v.47-54), estudiosos modernos não chegaram a um consenso da exata natureza patológica da moléstia. Ehrenberg supõe ter sido uma forma de febre tifoide (EHRENBERG, 2011, p. 216-217).
} 
suma, nosso ano de 2020 não aponta somente para uma renovação e surgimento de novas temáticas, mas igualmente para um direcionamento de reflexões, ponderações e considerações acerca do papel do historiador nestes novos tempos.

Agradecemos a todos os autores, colaboradores, leitores e pessoas que possibilitaram o lançamento desta edição. Desejamos a todos uma ótima leitura!

\section{Referências Bibliográficas}

The British Museum. Disponível em: <https://www.britishmuseum.org/ $>$. Acessado em 11 de maio de 2020

EHRENBERG, Victor. From Solon to Socrates. New York: Routledge Classics, 2011.

KOSSELLECK, Reinhart. História Magistra Vitae. In: Futuro Passado. Rio de Janeiro: Editora PUC-Rio, 2006, p. 41-60.

LÉVY, Pierre. A Metáfora do Hipertexto. In: As Tecnologias da Inteligência. Rio de Janeiro: Ed. 34, 1995, p. 21-73.

Louvre Museum Official Website. Disponível em: <https://www.louvre.fr/en>. Acessado em 10 de maio de 2020.

The Metropolitan Museum of Art: The Met Collection. Disponível em: <https://www.metmuseum.org/art/collection>. Acessado em 10 de maio de 2020.

Scielo em Perspectiva: O que é este tema dos preprints? Disponível em: <https://blog.scielo.org/blog/2016/11/22/o-que-e-este-tema-dos-preprints/\#.X03L1u$\underline{\text { SnIU> }}$. Acessado em 12 de julho de 2020.

VEYNE, Paul. Como se escreve a História. Brasília: Ed. da Universidade de Brasília, 1992. 